\title{
Dissipation, residues analysis and risk assessment of metconazole in grapes under field conditions
} using gas chromatography-tandem mass spectrometry

\author{
Wang Guo ${ }^{1,2 *}$, Yuling Chen ${ }^{2,3 *}$, Hui Jiao ${ }^{1,2}$, Deyu Hu ${ }^{1,2}$ Ping Lu ${ }^{1,2 *}$ \\ ${ }^{1}$ Key Laboratory of Green Pesticide and Agricultural Bioengineering, Ministry of Education, Guizhou University, Guiyang, \\ China; ${ }^{2}$ Center for Research and Development of Fine Chemicals Guiyang, Guizhou, China; ${ }^{3}$ Tongren Eco-Environment \\ Monitoring Center, Tongren, China
}

"These authors contributed equally to this work.

"Corresponding author: Ping Lu, Key Laboratory of Green Pesticide and Agricultural Bioengineering, Ministry of Education, Guizhou University, Guiyang 550025, China. Email: plu@gzu.edu.cn

Received: 27 September 2021; Accepted: 25 October 2021; Published: 10 December 2021

(c) 2021 Codon Publications

OPEN ACCESS CC) (1) (2) (2)

RESEARCH ARTICLE

\begin{abstract}
Metconazole (MEZ) is widely used in prevention and control of fruit and vegetable diseases. Here, a simple and reliable gas chromatography-tandem mass spectrometry (GC-MS/MS) method, using modified QuEChERS ("quick, easy, cheap, effective, rugged and safe") extraction method, was developed for determining the dissipation and residue of MEZ in grapes and soil, and the dietary risk of MEZ residues in grapes was evaluated for Chinese people. The average recoveries of MEZ in two matrices were $80.72-100.36 \%$ with relative standard deviations of $1.56-6.16 \%$. The same limits of detection and quantification in grapes and soil were $0.0006 \mathrm{mg} / \mathrm{kg}$ and $0.002 \mathrm{mg} /$ $\mathrm{kg}$, respectively. Under field conditions, the half-life of MEZ dissipation in grapes ranged from 11.75 to 20.39 days. The final residues of MEZ in grapes and soil ranged from $0.002 \mathrm{mg} / \mathrm{kg}$ to $0.19 \mathrm{mg} / \mathrm{kg}$ at pre-harvest intervals of 7, 14 and 21 days. The whole dietary risk assessment indicated acute hazard index and hazard quotient to be less than 1, implying the risk of MEZ was acceptable. This is the first study conducted on the dissipation, residue analysis and risk assessment of MEZ in grapes, thus providing reference for the detection and risk assessment of MEZ in other agricultural products.
\end{abstract}

Keywords: metconazole; grape; dissipation; residue risk assessment; GC-MS/MS

\section{Introduction}

Metconazole (MEZ; Figure 1), which is an effective foliar fungicide that acts by inhibiting the biosynthesis of ergosterol (Grayson et al., 1995), is widely used in agriculture to control fungal diseases such as powdery mildew, anthracnose and grey mould in grapes, cucumbers and wheat (Freitas et al., 2014; Duan et al., 2019; Zhu et al., 2020). According to the United States Environmental Protection Agency (USEPA; 2007), the oral acute lethal dose $\left(\mathrm{LD}_{50}\right)$ of MEZ in mice is $566 \mathrm{mg} / \mathrm{kg}$, which is a low-toxicity compound. Presently, MEZ has been registered in more than 40 countries worldwide, and is extensively used in Europe as well as China (Chen et al., 2017; Grayson et al., 1995). The use of MEZ significantly improves crop yield and quality of agricultural products, such as wheat (Deng et al., 2021; Duan et al., 2019, Li et al., 2019; Shi et al., 2020), oilseed rape (Liu et al., 2021), barley (Tateishi et al., 2014), cucumber (Zhu et al., 2020) and maize (Telenko et al., 2020). However, inappropriate 


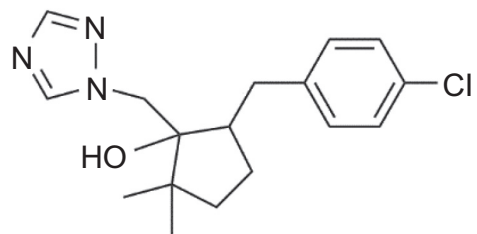

Figure 1. Chemical structure of metconazole.

and indiscriminate use and incorrect period of application of these pesticides lead to the presence of its residues on or in the applied crops, thus posing a hazard to the environment as well as humans through unintentional consumption of harmful pesticides. Although China has established the maximum residue limit (MRL) of MEZ for wheat (Chinese Ministry of Agriculture, 2021), no MRL of MEZ has been set up for other foods and crops. Therefore, it is important to study the dissipation pattern and residue analysis of MEZ, which is of great significance for routine food monitoring and risk assessment.

In recent years, various methods of analysis, including high-performance liquid chromatography ( $\mathrm{He}$ et al., 2017), ultra-high-performance liquid chromatography tandem mass spectrometry (Arthur et al., 2015), vortex-assisted liquid-liquid microextraction gas chromatography-tandem mass spectrometry (GC-MS/ MS) (Machado et al., 2019), and liquid chromatography-tandem quadrupole mass spectrometry (Barganska et al., 2018), have been reported for the measurement of MEZ in soil, flour, pollens, urine, honey and honeybee. GC-MS/MS is a powerful technique for determining pesticide residues because of its robustness, outstanding sensitivity and selectivity (Hernandez et al., 2013). However, to our knowledge, no research has been reported on the use of GC-MS/MS for residue analysis of MEZ in complex matrices such as vegetables and fruits.

In this study, a precise analytical method based on orthogonal experimentation to optimize pre-treatment combined with GC-MS/MS for the detection of MEZ residues in grapes and soil was established. Field trials of dissipation dynamics and final residues were investigated, and a risk assessment of MEZ in grapes for Chinese people based on field trial data was accomplished. This work would provide guidance for establishing an appropriate analytical approach for using MEZ in other agricultural products along with some useful information on the appropriate use of MEZ.

\section{Materials and Methods}

\section{Chemicals and reagents}

Metconazole standard (purity 99.0\%) was provided by Dr. Ehrenstorfer GmbH (Augsburg, Germany). Commercial formulation, suspension concentrate (SC) containing $8 \%$ MEZ, was supplied by Jiangsu Huifeng Agrochemical Co. Ltd. (Jiangsu, China). The graphitized carbon black (GCB) sorbent, C18 sorbent, and primary secondary amine (PSA) sorbent were bought from Agela Technologies Co. Ltd. (Tianjin, China). Chromatographic-grade acetone was bought from Chengdu Jinshan Chemical Reagent Co. Ltd. (Chengdu, China). Other analytical reagents were bought from Youpu Reagent Co. Ltd. (Tianjin, China).

\section{Preparation of standard solutions}

A standard stock solution of MEZ (200 mg/L) was prepared in chromatography-grade acetone, and the working standard solutions with the concentrations of 0.01 , $0.02,0.2,0.5,1.0$ and $2.0 \mathrm{mg} / \mathrm{L}$ were obtained by serially diluting stock solution with chromatography-grade acetone. The matrix-matched standard solutions of MEZ were prepared with an extract of blank grapes and soil for calibration and quantification. All standard solutions were stored in dark at $4^{\circ} \mathrm{C}$.

\section{Field trials}

The field trials were performed at two sites of China: Suzhou (Anhui Province, $116^{\circ} 93^{\prime} \mathrm{E}$ and $34^{\circ} 19^{\prime} \mathrm{N}$ ), which has a temperate semi-humid monsoon climate, and Guiyang (Guizhou Province, $106^{\circ} 22^{\prime} \mathrm{E}$ and $26^{\circ} 18^{\prime} \mathrm{N}$ ), which has a subtropical plateau monsoon humid climate. All trials observed the guidelines on pesticide residue trials issued by the Ministry of Agriculture, People's Republic of China (Liu et al., 2004). The trials were carried out between June 2016 and September 2016, and the experiments were repeated during the same period in 2017. The annual precipitation in Guizhou and Anhui Provinces was $630 \mathrm{~mm}$ and $800 \mathrm{~mm}$, respectively. The average air temperature in Guizhou Province was $22.3^{\circ} \mathrm{C}$ and that in Anhui Province was $19.4^{\circ} \mathrm{C}$. The average solar radiation in Guizhou Province was $4.0 \mathrm{kWh} / \mathrm{m}$ per day and that in Anhui Province was $3.3 \mathrm{kWh} / \mathrm{m}$ per day. Soil at Guizhou and Anhui sites was silt loam and sandy clay loam with an organic matter of $16.29 \mathrm{~g} / \mathrm{kg}$ and $9.54 \mathrm{~g} / \mathrm{kg}$ and $\mathrm{pH}$ of 7.98 and 8.58, respectively. Each experimental plot contained three replicate plots and an untreated plot, a control, and the area of each plot was $30 \mathrm{~m}^{2}$. To avoid cross-contamination, a buffer zone separated each test plot.

\section{Sampling procedure}

The analyzing dissipation, MEZ (SC, 8\%) was dissolved in water and applied to grapes (half the size of ripe) and soil at $90 \mathrm{~g}$ a.i./ha using a knapsack sprayer. Grape samples 
(not less than $2 \mathrm{~kg}$ ) and soil samples (not less than $1 \mathrm{~kg}$ ) were collected at random intervals of $2 \mathrm{~h}$ on day $1,3,5,7$, 10, 14, 21 and 28 after application at different directions and locations of each plot.

For terminal residue trials, MEZ (SC, 8\%) was applied to grapes and soil at $60 \mathrm{~g}$ a.i./ha (recommended dose) and $90 \mathrm{~g}$ a.i./ha, respectively, at 7-day intervals. Both grape and soil samples were collected randomly at different orientations and locations from each plot on day 7, 14 and 21 before harvest.

The diseased particles were discarded, and the stalks were removed from the grape samples. Stones and weeds were removed from the soil samples. All samples were homogenized, bagged and transported to laboratory. The grape samples were shredded and mashed using a vegetation disintegrator, and each sample was thoroughly blended. The collected grape and soil samples were stored at $-20^{\circ} \mathrm{C}$ until further analysis.

\section{Sample extraction and cleanup}

For analysis, 10-g aliquots of grape and soil samples were weighed in $50-\mathrm{mL}$ polyethylene centrifuge tubes and extracted with $20-\mathrm{mL}$ acetonitrile. The tubes were capped and shaken vigorously for $3 \mathrm{~min}$ at 2,500 rpm and added 3-g NaCl and 4-g anhydrous $\mathrm{MgSO}_{4}$. The mixture was vortexed for $2 \mathrm{~min}$ and centrifuged at 6,000 rpm for 5 min. Subsequently, $10 \mathrm{~mL}$ of supernatant was accurately pipetted into a round-bottomed flask, rotary-evaporated (in a water bath at $40^{\circ} \mathrm{C}$ ) to dryness under vacuum. Acetone $(1 \mathrm{~mL})$ was added to dissolve evaporated residues, and the mixture was transferred to a $2-\mathrm{mL}$ centrifuge tube. Then 50-mg C18 and 50-mg PSA were added for the dispersive solid-phase extraction cleanup. The mixture was vortexed for $1 \mathrm{~min}$, followed by centrifuging for $5 \mathrm{~min}$ at a speed of 10,000 rpm. The upper organic layer was filtered through a $0.22-\mu \mathrm{m}$ nylon filter and transferred to a vial for GC-MS/MS analysis.

\section{Instrumentation and GC-MS/MS analytical conditions}

Measurements were carried out using a TSQ 8000 Evo triple quadrupole mass spectrometer connected to a Trace 1310 GC (Thermo Fisher Scientific, San Jose, CA, USA). Samples were injected with TriPlus RSH automatic sampler into a programmed temperature vaporization (PTV) injector. Chromatographic separation was performed using a ThermoFisher Scientific capillary column TG-5 MS analytical column $(30-\mathrm{m} \times 250-\mu \mathrm{m} \times 0.25-\mu \mathrm{m}$ thick film) at a flow rate of $1.2 \mathrm{~mL} / \mathrm{min}$ using helium (99.9999\%) as a carrier gas. About $1 \mu \mathrm{L}$ was injected using a $2-\mathrm{mm}$ inner diameter (i.d.) $\times$ 2.75-mm $\times 120-\mathrm{mm}$ PTV metal liner (Thermo Fisher Scientific) in a split less mode with a split flow of $50 \mathrm{~mL} / \mathrm{min}$ and split less time of $2.0 \mathrm{~min}$. The oven temperature was set at $120^{\circ} \mathrm{C}$ (held for $1 \mathrm{~min}$ ), then ramped up to $300^{\circ} \mathrm{C}$ at $25^{\circ} \mathrm{C} / \mathrm{min}$ and maintained for $5 \mathrm{~min}$. The PTV injector was initially set at $100^{\circ} \mathrm{C}$ (held for $1 \mathrm{~min}$ ), ramped up to $300^{\circ} \mathrm{C}$ at $25^{\circ} \mathrm{C} / \mathrm{s}$ and maintained for $1 \mathrm{~min}$. For cleaning, the temperature was raised to $350^{\circ} \mathrm{C}$ at a rate of $12^{\circ} \mathrm{C} / \mathrm{s}$ and maintained for $10 \mathrm{~min}$. The overall running time was $13.20 \mathrm{~min}$. The temperatures of ion source and mass spectrometry transmission line were $300^{\circ} \mathrm{C}$ and $280^{\circ} \mathrm{C}$, respectively. Argon (99.999\%) was used as a collision gas in electron ionization mode with an electron energy of $70 \mathrm{eV}$, at an emission current of $50 \mu \mathrm{A}$, and a total scan time set at $300 \mathrm{~ms}$. Data were acquired and processed using the TraceFinder ${ }^{\mathrm{Tm}}$ software (version 3.3).

\section{Method validation parameters}

Calibration equation for target analyte was established by plotting the concentration of calibration standard with the peak area matched to the matrix of concern (Li et al., 2017a). The linearity of calibration curve was assessed by determining coefficient $\left(R^{2}\right)$ at six concentration points ranging from $0.01 \mathrm{mg} / \mathrm{L}$ to $2.00 \mathrm{mg} / \mathrm{L}$ using matrixmatched calibration standards for quantification.

The matrix effect (ME\%) was calculated using the following equation (Mondal et al., 2017):

$$
\mathrm{ME} \%=\frac{\begin{array}{c}
\text { peak area of the matrix standard }- \\
\text { peak area of the solvent standard }
\end{array}}{\text { peak area of the solvent standard }} \times 100 \text {, }
$$

where $\mathrm{ME} \%=0$ indicated no matrix effect, $\mathrm{ME} \%>$ 0 represented enhancement, and $\mathrm{ME}<0$ described suppression.

The limit of detection (LOD) was evaluated at a signalto-noise $(\mathrm{S} / \mathrm{N})$ ratio of $3: 1$. The limit of quantification (LOQ) was defined as the lowest spiked concentration level of analyte in a matrix with an S/N ratio of 10:1(Chen et al., 2018).

Recovery experiments were conducted at three spiked levels $(0.002,0.02$ and $0.2 \mathrm{mg} / \mathrm{kg})$ with five duplications of blank grapes and soil. The method of accuracy and precision parameters, expressed as average recovery and relative standard deviation (RSD), yielded a satisfactory recovery of $70-120 \%$ and an $\mathrm{RSD} \leq 20 \%$ for the successful evaluation of analytical methodology of pesticide residues (Liu et al., 2004).

In order to evaluate the repeatability and reproducibility of the established method, intra- and inter-day recovery 
experiments were conducted (Biswas et al., 2019). The intra-day reproducibility of analytical method was assessed by contrasting the RSD values of the recoveries of spiked samples at three concentrations in five replicates and analyzed on the same day. The inter-day reproducibility of the established method was measured by analyzing spiked samples on three consecutive days.

\section{Dissipation kinetics}

The dissipation curves of MEZ were plotted using nonlinear regression with Microsoft Excel 2016. Dissipation concentrations of MEZ over time in grapes and soil were calculated using the following equations (Chen et al., 2016):

$$
\begin{gathered}
C_{t}=C_{0} \times e^{-k t}, \\
\mathrm{t}_{1 / 2}=\frac{\ln 2}{\mathrm{k}},
\end{gathered}
$$

where $C_{\mathrm{t}}(\mathrm{mg} / \mathrm{kg})$ is the volume of MEZ at time $t$ (days), $C_{0}(\mathrm{mg} / \mathrm{kg})$ is the initial concentration, and $\mathrm{k}$ is the rate constant.

\section{Dietary intake risk assessment}

The risk of acute and chronic dietary exposure to MEZ through consumption of grapes was calculated according to the guidelines published by the Food and Agriculture Organization of the United Nations (FAO) and the World Health Organization (WHO). The acute assessment was carried out using the following equations (Szpyrka et al., 2015):

$$
\begin{gathered}
\text { IESTI }=\frac{\mathrm{LP} \times \mathrm{HR} \times \mathrm{v}}{\mathrm{bw}}, \\
\mathrm{aHI}=\frac{\mathrm{IESTI}}{\mathrm{ARfD}},
\end{gathered}
$$

where IESTI denotes the estimated short-term intake ( $\mathrm{mg} / \mathrm{kg}$ of body weight [bw]); HR is the highest residue level (mg/kg) (FAO/WHO, 2009); LP represents the large portion consumption of grapes $(\mathrm{kg} /$ day, 97.5 th percentile of eaters); $v$ represents the variability factor; ARfD is the acute reference dose $(\mathrm{mg} / \mathrm{kg} \mathrm{bw})$; and aHI is the acute hazard index.

The following equations were used for chronic dietary risk assessment (Wang et al., 2018a):

$$
\mathrm{EDI}=\frac{\mathrm{STMR} \times \mathrm{Fi}}{\mathrm{bw}}
$$

$$
\mathrm{HQ}=\frac{\mathrm{EDI}}{\mathrm{ADI}}
$$

where EDI represents the estimated daily intake $(\mathrm{mg} /$ $\mathrm{kg}$ bw); STMR represents the supervised trials median residue $(\mathrm{mg} / \mathrm{kg})$; if no STMR was available, the corresponding MRL values were used for these calculations (Chen et al., 2018). Fi denotes the consumption of grapes (kg/day), HQ represents the hazard quotient, and ADI denotes the acceptable daily intake ( $\mathrm{mg} / \mathrm{kg}$ bw). Both HQ and $\mathrm{aHI}<1$ indicate that the risk of MEZ is acceptable for consumers. On the contrary, if $\mathrm{HQ}$ or aHI $>1$, then it indicates that the risk of MEZ is unacceptable for consumer health (Wang et al., 2018b).

\section{Results and discussion}

\section{Optimization of GC-MS/MS conditions}

The optimised triple-quadrupole MS/MS data acquisition parameters play important roles in analyzing the target compounds. The first step in optimization is to inject $1.0-\mathrm{mg} / \mathrm{L}$ standard solution in full-scan mode and use the NIST MS Search 2.2 ChemStation program to confirm that the peaks correspond to the target compounds. The retention time was confirmed, and the appropriate precursor ions were selected. The ion with higher mass-tocharge $(\mathrm{m} / \mathrm{z})$ ratio and in abundance is usually selected to increase sensitivity. Subsequently, the target compounds were monitored using two or three high-intensity selected reaction monitoring (SRM) transitions to further optimize the generation of MS/MS product ions: the most sensitive one is the quantified product ion, and the other is the qualifying product ion. The collision energy voltages (potential on second quadrupole) were autonomously optimized through collision energy tests using the Auto SRM program, which could select appropriate collision energy of each ion. The initial selected three transitions were m/z $125>63,125>99$ and $125>90$. However, an interference peak appeared when transition $\mathrm{m} / \mathrm{z} 125$ $>99$. If the spiking grape samples were at $0.02 \mathrm{mg} / \mathrm{L}, \mathrm{m} / \mathrm{z}$ $125>63$ and $125>90$ were selected to analyze MEZ in positive mode. The optimized collision energy was $30 \mathrm{~V}$ and $20 \mathrm{~V}$ for product ions 63 and 90, respectively.

\section{Optimization of sample preparation}

In order to optimize the sample preparation method for testing MEZ in both matrices, the effects of extraction solvents, extraction doses, extraction period and sorbents were studied.

Based on the physicochemical properties of MEZ, acetonitrile, dichloromethane, ethyl acetate, and acetone 
were selected as extraction solvents. As shown in Figure 2a, recovery of MEZ in soil was $92.26 \%$ (acetonitrile), 82.24\% (dichloromethane), 82.96\% (ethyl acetate), and $76.85 \%$ (acetone); and recovery of MEZ in grapes was 93.95\% (acetonitrile), 80.34\% (dichloromethane), 83.16\% (ethyl acetate), and $77.63 \%$ (acetone). The results indicated that acetonitrile was the best extractant. In order to ensure adequate extraction of MEZ from the samples, the effects of volume of acetonitrile $(10,20$ and $30 \mathrm{~mL})$ and extraction time (1, 3 and $5 \mathrm{~min}$ ) on the extraction efficiency of the samples were evaluated successively. The results demonstrated (Figures $2 \mathrm{~b}$ and $2 \mathrm{c}$ ) that the highest recovery of MEZ was $91.3 \%$ (soil) and $92.1 \%$ (grapes) with $20 \mathrm{~mL}$ of acetonitrile and an extraction time of $5 \mathrm{~min}$. We also considered the effects of sorbents on extraction, for which four sorbents were selected, namely PSA (100 mg), C18 (100 mg), GCB (100 mg), and C18 + PSA (50 mg each). The results are shown in Figure $2 \mathrm{~d}$. The recovery of MEZ in soil was $85.9 \%$ (100mg PSA), 85.06\% (100-mg C18), 54.78\% (100-mg GCB), 97.54\% (50-mg C18 + 50-mg PSA); and the recovery of MEZ in grapes was $85.52 \%$ (100-mg PSA), 88.84\% (100mg C18), 58.20\% (100-mg GCB), 102.28\% (50-mg C18 + 50 -mg PSA). Therefore, the combination of PSA (50 mg) and $\mathrm{C} 18(50 \mathrm{mg})$ adsorbent was chosen due to maximum recovery of MEZ in grapes and soil. All the above RSD values were less than $5 \%$.
We also evaluated the detection methods of MEZ in grapes and soil by analysis of variance (ANOVA) using the Microsoft Excel 2016 software. The type and amount of extraction solvent, extraction time and absorbent were studied to determine the best pre-treatment conditions and the variable with the most significant effect on the analysis of MEZ. Supplementary Tables S1-S4 (Supplementary Material) show the analytical data of nine orthogonal experiments with four factors and three levels $\left[\mathrm{L}_{9}\left(3^{4}\right)\right]$. All the experiments demonstrated that the optimum pre-treatment condition to analyze MEZ was the type of extraction solution applied, and the highest response value was $\mathrm{A}_{2} \mathrm{~B}_{2} \mathrm{C}_{3} \mathrm{D}_{1}$. As the $F$-ratio (3.207 for soil and 3.417 for grape) was more than $F$-critical value (3.110), all response values were affected by the type of extraction solution applied. The optimum extractant for MEZ was acetonitrile; all other conditions could be set to any parameter within its investigated range.

\section{Method performance}

Validation was performed to evaluate the following parameters of analytical method: linearity, accuracy, precision, sensitivity, matrix effect, LOD, and LOQ (Zhang et al., 2016a. All results are summarized in
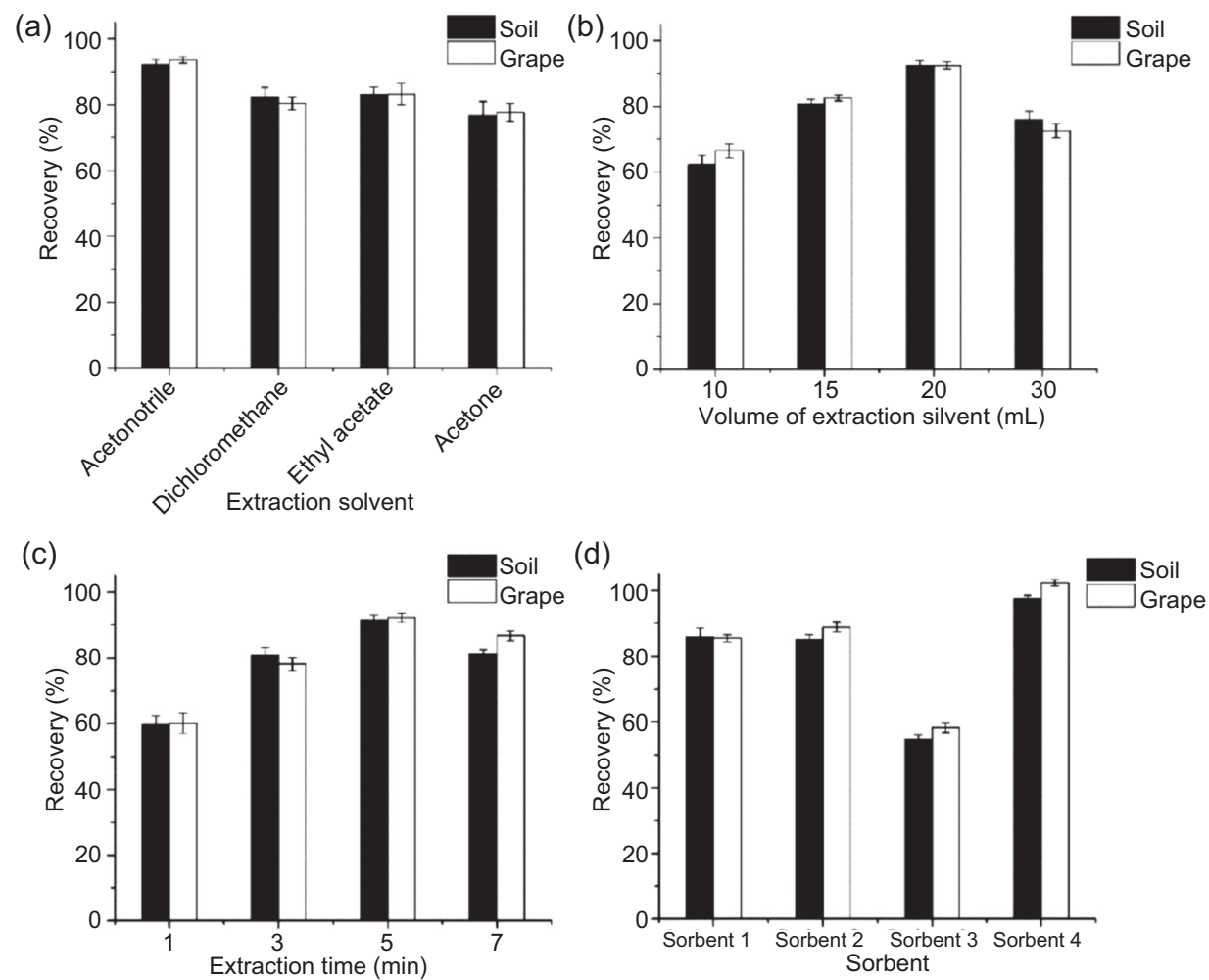

Figure 2. Optimization of sample preparation conditions. (A) Extraction solvent, (B) volume of extraction solvent, (C) extraction time and (D) sorbent. Sorbent 1 is primary secondary amine (PSA), sorbent 2 is C18, sorbent 3 is graphitized carbon black (GCB), and sorbent 4 is PSA + C18. Metconazole were fortified at $0.02 \mathrm{mg} / \mathrm{kg}$ for both grape and soil samples $(n=3)$. 
Table 1. Calibration equation, $R^{2}, M E \%$, limit of quantification (LOQ) and limit of detection (LOD) of metconazole in solvent and matrices.

\begin{tabular}{llcccc} 
Matrices & Calibration equation & $R^{2}$ & ME $\%$ & LOD (mg/kg) & LOQ (mg/kg) \\
\hline n-Acetone & $y=7,47,116 x-19,739$ & 0.9995 & - & - & - \\
Grapes & $y=7 \times 10^{6} x-10,5511$ & 0.9996 & 30.72 & 0.0006 & 0.002 \\
Soil & $y=9 \times 10^{6} x-18,466$ & 1.0000 & 19.92 & 0.0006 & 0.002 \\
\hline
\end{tabular}

Tables 1 and 2, and the representative chromatograms of MEZ are presented in Supplementary Figure S1.

Good linearity and excellent correlation in all matrices matched calibration equations with $R^{2}>0.99$. The respective average recovery of MEZ in grapes and soil ranged from $80.72 \%$ to $93.56 \%$ and $82.83 \%$ to $100.36 \%$ with RSD of $1.56-6.16 \%$ (intra-day) and $2.24-5.26 \%$ (inter-day), indicating that the established method has satisfactory precision and accuracy. The response of MEZ was enhanced in the matrices of grape and soil because of matrix effect $>0$ (30.72 and 19.92, respectively). Hence in this study, matrix-matched external calibration was used to eliminate the impact of matrix for quantification. In grapes and soil, the same values LOD and LOQ were $0.0006 \mathrm{mg} / \mathrm{kg}$ and $0.002 \mathrm{mg} / \mathrm{kg}$, respectively. Overall, in the present study, the optimized data of the method demonstrated satisfactory linearity, precision, accuracy, and sensitivity; thus, it is appropriate for determining MEZ in grapes and soil.

\section{Dissipation behavior of MEZ in field grape and soil}

The dissipation curves of MEZ for grapes and soil for 2 years at Guizhou and Anhui Provinces are shown in Figure 3.

It was easily observed that the trend of MEZ was similar in all grape samples as MEZ residues in grapes decreased significantly with passage of time. The initial deposition of MEZ in grapes after $2 \mathrm{~h}$ of spraying was $0.16-0.20 \mathrm{mg} / \mathrm{kg}$. As observed, the MEZ residue decreased to $50 \%$ of the initial concentration after 14 days. At the end of sampling period, the residue of MEZ in grapes was already below $0.06 \mathrm{mg} / \mathrm{kg}$. All dissipation processes followed first-order kinetics.

In 2016, the dynamic equations of MEZ were as follows: $C \mathbf{t}=0.1879 \mathrm{e}^{-0.032 t}, R^{2}=0.8402$ (Guizhou Province), and $C \mathbf{t}$ $=0.1085 \mathrm{e}^{-0.059 t}, R^{2}=0.8856$ (Anhui Province), with respective half-life of 21.66 and 11.75 days.

In 2017, MEZ dissipation followed the first-order kinetics of $C \mathbf{t}=0.1907 \mathrm{e}^{-0.036 t}, R^{2}=0.8954$ (Guizhou Province) and $C \mathbf{t}=0.1826 \mathrm{e}^{-0.045 t}, R^{2}=0.8974$ (Anhui Province), with respective half-life of 19.25 and 15.40 days. Although the initial concentrations of MEZ residues in grapes were similar for 2 years, the half-life was different between the two locations. This could be due to different atmospheric conditions, type of application, physicochemical properties of pesticides, growth dilution factors and plant characteristics (Fantke et al., 2013; Ma et al., 2018; Malhat et al., 2013).

The initial concentration values of MEZ residues in soil were nearly similar at the two sites-Anhui Province: $0.13 \mathrm{mg} / \mathrm{kg}$ for 2016 and $0.16 \mathrm{mg} / \mathrm{kg}$ for 2017, and at Guizhou Province: $0.10 \mathrm{mg} / \mathrm{kg}$ for 2016 and $0.11 \mathrm{mg} / \mathrm{kg}$ for 2017. The MEZ residues in soil decreased with time at Anhui Province (2016). After 14 days, the MEZ residue in soil was already below 50\%, and the final MEZ residue in soil at the end of the experiment (after 28 days) was $0.04 \mathrm{mg} / \mathrm{kg}$. The dissipation process followed the first-order kinetics, and the dynamic equation of MEZ was $C \mathbf{t}=$ $0.0998 \mathrm{e}^{-0.034 \mathrm{t}}$ and $R^{2}=0.7887$, with a half-life of 20.39 days. However, for other soil samples, the MEZ residue in soil did not follow the first-order dissipation. Therefore,

Table 2. Average recoveries and relative standard deviation (RSD) of metconazole under various matrices and spiked levels.

\begin{tabular}{|c|c|c|c|c|c|}
\hline \multirow[t]{2}{*}{ Matrices } & \multirow[t]{2}{*}{ Spiked level (mg/kg) } & \multicolumn{2}{|c|}{ Intra-day $(n=5)$} & \multicolumn{2}{|c|}{ Inter-day $(n=15)$} \\
\hline & & Average recovery (\%) & RSD (\%) & Average recovery (\%) & RSD (\%) \\
\hline \multirow[t]{3}{*}{ Grapes } & 0.002 & 88.04 & 2.14 & 88.77 & 3.45 \\
\hline & 0.02 & 91.15 & 2.27 & 93.56 & 3.76 \\
\hline & 0.2 & 80.72 & 1.56 & 81.27 & 2.24 \\
\hline \multirow[t]{3}{*}{ Soil } & 0.002 & 100.36 & 2.94 & 97.89 & 3.12 \\
\hline & 0.02 & 82.83 & 6.16 & 82.85 & 5.26 \\
\hline & 0.2 & 94.08 & 2.58 & 96.86 & 3.65 \\
\hline
\end{tabular}


(a)
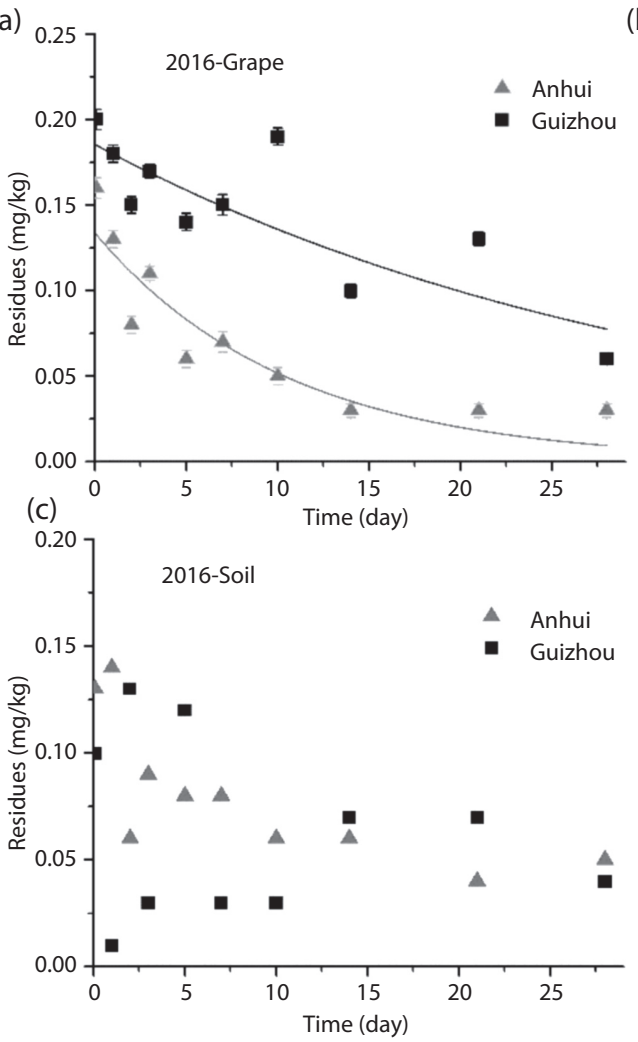

(b)
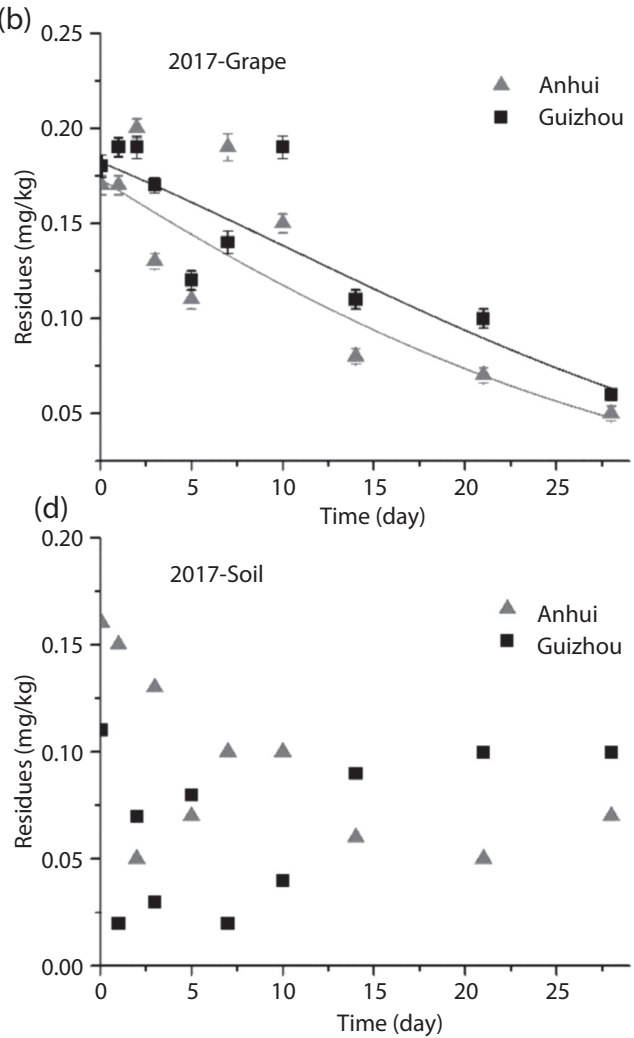

Figure 3. Dissipation of MEZ in grapes and soil at Guizhou and Anhui Provinces. (A) 2016, grapes; (B) 2017, grapes; (C) 2016, soil; (D) 2017, soil.

half-life in 2016 (Guizhou Province) and 2017 could not be calculated. In general, the dissipation of pesticide in soil was affected by many factors, including soil type, soil water content, $\mathrm{pH}$, clay, climate, microorganisms, physical properties of soil, and organic matter (Liang et al., 2013; Singh et al., 2015; Zhang et al., 2016b).

\section{Terminal residues of MEZ in grapes and soil}

The terminal residues of MEZ in grape and soil samples collected at Guizhou and Anhui Provinces are summarized in Supplementary Table S5. The results indicated that after two or three sprays of $60 \mathrm{~g}$ a.i./ha (recommended dose) on grapes, the terminal residues of MEZ ranged from 0.03 to $0.19 \mathrm{mg} / \mathrm{kg}$ after 7 days, 0.002 to $0.03 \mathrm{mg} / \mathrm{kg}$ after 14 days and $<0.002$ to $0.02 \mathrm{mg} / \mathrm{kg}$ after 21 days. If $90 \mathrm{~g}$ a.i./ha (1.5 times the recommended dose) of MEZ was applied, then the final residue levels were $<0.002-0.14 \mathrm{mg} / \mathrm{kg}$ after 7 days, $<0.002-0.07 \mathrm{mg} / \mathrm{kg}$ after 14 days and $<0.002-0.03 \mathrm{mg} / \mathrm{kg}$ after 21 days. In 2016 and 2017, the final residue levels were $<0.002-0.19 \mathrm{mg} /$ $\mathrm{kg}$ at Guizhou Province and $0.01-0.07 \mathrm{mg} / \mathrm{kg}$ at Anhui Province; this revealed little difference between the degradation of MEZ in grape samples from the two locations. The residue levels of MEZ in grapes were different at places, which could have been due to different growth of plants, uneven application or different climatic conditions at the two sites (Li et al., 2017b). The terminal residues of MEZ in grape samples collected 21 days after the last application of MEZ were lower than the MRL value of $0.02 \mathrm{mg} / \mathrm{kg}$ (Council of the European Union 2016, European pesticides database).

The results demonstrated that the terminal residue levels of MEZ in soil at Guizhou Province after the last application of MEZ were as follows: $<0.002-0.03 \mathrm{mg} / \mathrm{kg}$ (7 days), $<0.002-0.02 \mathrm{mg} / \mathrm{kg}$ (14 days) and $<0.002-0.01 \mathrm{mg} / \mathrm{kg}(21$ days). The residue levels of MEZ in soil at Anhui Province after the last application of MEZ were as follows: 0.01$0.04 \mathrm{mg} / \mathrm{kg}$ (7 days), $0.01-0.06 \mathrm{mg} / \mathrm{kg}$ (14 days) and $0.01-0.02 \mathrm{mg} / \mathrm{kg}$ (21 days). No apparent relationship was determined between the residue levels and the time, dose and interval of spraying. In most cases, the residue levels of MEZ in soil at Guizhou Province were lower than those at Anhui Province, possibly because of the higher amount of soil organic matter at Guizhou than at Anhui (Lopez-Fernandez et al., 2016).

\section{Dietary intake risk assessment}

The dietary intake risk assessment of MEZ was conducted using the terminal residual data of field experiments, 
Table 3. Acute intake assessment results of the highest pesticide residues from supervised field trials.

\begin{tabular}{lccccc} 
PHI (day) & HR (mg/kg) & LP (kg/d) & ARfD (mg/kg bw) & IESTI (mg/kg bw) & aHI \\
\hline 7 & 0.19 & & & 0.00542 & 0.542 \\
14 & 0.07 & 0.5703 & 0.01 & 0.00200 & 0.200 \\
21 & 0.03 & & 0.00086 & 0.086 \\
\hline
\end{tabular}

PHI: pre-harvest interval; HR: highest residue level; LP: large portion consumption of grapes; ARfD: acute reference dose; IESTI: estimated short-term intake of grapes; aHl: acute hazard index.

Table 4. The whole dietary risk assessment of metconazole on Chinese dietary pattern.

\begin{tabular}{|c|c|c|c|c|c|c|}
\hline Classification & $\mathrm{Fi}(\mathrm{kg})$ & $\begin{array}{l}\text { Reference residue } \\
\text { limits }(\mathrm{mg} / \mathrm{kg})\end{array}$ & Sources & EDI (mg/kg bw) & $\begin{array}{c}\text { ADI } \\
\text { (mg/kg bw) }\end{array}$ & $H Q$ \\
\hline Rice and its products & 0.2399 & 0.02 & EU & 0.004798 & $0.01 \times 63$ & \\
\hline Flour and its products & 0.1385 & 0.1 & China & 0.01385 & & \\
\hline Other cereals & 0.0233 & 5 & Japan & 0.1165 & & \\
\hline Tubers & 0.0495 & 0.04 & EU & 0.00198 & & \\
\hline Dried beans and their products & 0.016 & 0.2 & Japan & 0.0032 & & \\
\hline Dark vegetable & 0.0915 & 0.02 & EU & 0.00183 & & \\
\hline Light vegetable & 0.1837 & 0.02 & EU & 0.003674 & & \\
\hline Pickles & 0.0103 & & & & & \\
\hline Fruits & 0.0457 & 0.02 & STMR & 0.000914 & & \\
\hline Nuts & 0.0039 & 0.05 & EU & 0.000195 & & \\
\hline Livestock and poultry & 0.0795 & & & & & \\
\hline Milk and its products & 0.0263 & 0.02 & EU & 0.000526 & & \\
\hline Egg and its products & 0.0236 & 0.02 & EU & 0.000526 & & \\
\hline Fish and shrimp & 0.0301 & & & & & \\
\hline Vegetable oil & 0.0327 & & & & & \\
\hline Animal oil & 0.0087 & & & & & \\
\hline Sugar, starch & 0.0044 & & & & & \\
\hline Salt & 0.012 & & & & & \\
\hline Soy sauce & 0.009 & & & & & \\
\hline Total & 1.0286 & & & 0.147993 & 0.63 & 0.23491 \\
\hline
\end{tabular}

ADI: acceptable daily intake; EDI: estimated daily intake; STMR: supervised trials median residue; Fi: the dietary reference intake of a certain kind of food used to plan and assess nutrient intakes of healthy Chinese people.

toxicity data for the fungicide and data on grape consumption by different groups of population in China. The LOQ values were used for intake calculations when the terminal residual were under the LOQ values (Shi et al., 2015).

The acute risk assessment of MEZ in grapes is summarised in Table 3. As observed, the HR values of MEZ in grapes were $0.19,0.07$ and $0.03 \mathrm{mg} / \mathrm{kg}$ at intervals of 7,14 and 21 days, respectively. The normal adult mean body weight was $60 \mathrm{~kg}$ (Huang et al., 2015). According to the World Health Organization (WHO, 2015), LP of grapes is $0.5703 \mathrm{~kg} /$ day for Chinese, single grape fruit weight is $0.6366 \mathrm{~kg}$, variability factor of grapes is 3 . According to the European pesticides database (Council of the European Union), ARfD for MEZ is $0.01 \mathrm{mg} / \mathrm{kg} \cdot \mathrm{bw}$. As shown in Supplementary Table S1, all of the computed aHI values of MEZ were less than 1 , and the aHI value decreased with increase in the number of sampling days. Therefore, we conclude that the acute dietary exposure risk is acceptable.

The ADI values OF MEZ were $0.01 \mathrm{mg} / \mathrm{kg} \cdot \mathrm{bw}$ (Chinese Ministry of Agriculture, 2021). The calculation of EDI value of MEZ in the chronic dietary risk assessment is based on the Chinese dietary model, and the only crop currently registered is wheat, with the MRL of $0.1 \mathrm{mg} / \mathrm{kg}$ as the reference limit. European Union (EU) has the largest number of registered MEZ crops with the most stringent limits of pesticide residues. Since both Japan and China are Asian countries, we chose the highest value of 
Table 5. Dietary risk of applied MEZ on grapes for Chinese people of different genders and age groups.

\begin{tabular}{|c|c|c|c|c|c|}
\hline Age (years) & Gender & Body weight (kg) & Fruit intake (kg/day) & EDI (mg/kg bw) & $H Q$ \\
\hline \multirow[t]{2}{*}{$2-3$} & Man & 13.2 & 0.0437 & 0.0001655 & 0.01655 \\
\hline & Woman & 12.3 & 0.0444 & 0.0001805 & 0.01805 \\
\hline \multirow[t]{2}{*}{$4-6$} & Man & 16.8 & 0.0472 & 0.0001405 & 0.01405 \\
\hline & Woman & 16.2 & 0.0514 & 0.0001586 & 0.01586 \\
\hline \multirow[t]{2}{*}{$7-10$} & Man & 22.9 & 0.0471 & 0.0001028 & 0.01028 \\
\hline & Woman & 21.7 & 0.0469 & 0.0001081 & 0.01081 \\
\hline \multirow[t]{2}{*}{$11-13$} & Man & 34.1 & 0.047 & 0.0000689 & 0.00689 \\
\hline & Woman & 34.0 & 0.0456 & 0.0000671 & 0.00671 \\
\hline \multirow[t]{2}{*}{$14-17$} & Man & 46.7 & 0.0485 & 0.0000519 & 0.00519 \\
\hline & Woman & 45.2 & 0.0581 & 0.0000643 & 0.00643 \\
\hline \multirow[t]{2}{*}{$18-29$} & Man & 58.4 & 0.0418 & 0.0000358 & 0.00358 \\
\hline & Woman & 52.1 & 0.0529 & 0.0000508 & 0.00508 \\
\hline \multirow[t]{2}{*}{$30-44$} & Man & 64.9 & 0.0359 & 0.0000277 & 0.00277 \\
\hline & Woman & 55.7 & 0.0454 & 0.0000408 & 0.00408 \\
\hline \multirow[t]{2}{*}{$45-59$} & Man & 63.1 & 0.0321 & 0.0000254 & 0.00254 \\
\hline & Woman & 57.0 & 0.0373 & 0.0000327 & 0.00327 \\
\hline \multirow[t]{2}{*}{$60-69$} & Man & 61.5 & 0.0338 & 0.0000275 & 0.00275 \\
\hline & Woman & 54.3 & 0.0348 & 0.000032 & 0.00320 \\
\hline \multirow[t]{2}{*}{$\geq 70$} & Man & 58.5 & 0.027 & 0.0000231 & 0.00231 \\
\hline & Woman & 51.0 & 0.0217 & 0.0000213 & 0.00213 \\
\hline
\end{tabular}

EDI: Estimated daily intake; $\mathrm{HQ}$ : hazard quotient.

MRL for each food group for the purpose of calculation. The data of whole dietary risk assessment of MEZ on Chinese dietary pattern are shown in Table 4. The STMR value of $0.02 \mathrm{mg} / \mathrm{kg}$ for MEZ was used to calculate EDI. The HQ value of MEZ was 0.23491 , which was less than 1 , thus establishing that the dietary risk of MEZ application to grapes is acceptable.

We also assessed the dietary risk of applied MEZ on grapes to Chinese people of both genders belonging to different age groups. Average fruit intake and average body weight (male and female) of 10 population subgroups (Jin, 2008) are given in Table 5. As shown in the table, the HQ values for children were higher than those for adults among different groups, and the HQ values for females were more than that for males in the same age group. Therefore, MEZ, in general, has more risk for females and children than for males and adults. However, all HQ values of MEZ for grapes ranged from 0.00231 to 0.01805 , which were far below 1 , signifying that spraying $\mathrm{MEZ}$ on grapes at a recommended dose possibly is not a health concern for humans.

\section{Conclusions}

In this paper, a GC-MS/MS analytical method was developed to estimate the dissipation behavior, residues, and safety evaluation of MEZ in grapes and soil. Based on the results of linearity, accuracy, precision, repeatability, reproducibility, and sensitivity of the method, the method was deemed to be acceptable for qualitative and quantitative analyses of MEZ. In the study of dissipation, MEZ followed the first-order dynamic model in grapes and soil. The terminal residues of MEZ in grapes and soil were $<0.002-0.19 \mathrm{mg} / \mathrm{kg}$ and $<0.002-0.06 \mathrm{mg} / \mathrm{kg}$, respectively. The data of the intake risk of MEZ demonstrated that both aHI and HQ values were less than 1, which indicated that MEZ residues from consumption of grapes do not pose a potential risk for Chinese people. This study could offer a reference for dissipation and residue analysis of MEZ for other agricultural products as well as provide basic data for the safe use and maximum residue limit of MEZ for grapes in China.

\section{References}

Arthur, D., Botias, C., Alaa, A-S., Goulson, D. and Hill, E.M., 2015. Sensitive determination of mixtures of neonicotinoid and fungicide residues in pollen and single bumblebees using a scaled down QuEChERS method for exposure assessment. Analytical and Bioanalytical Chemistry 407: 8151-8162. https://doi. org/10.1007/s00216-015-8986-6.

Barganska, Z., Konieczka, P. and Namiesnik, J., 2018. Comparison of two methods for the determination of selected pesticides in 
honey and honeybee samples. Molecules 23: 1-13. https://doi. org $/ 10.3390 /$ molecules 23102582.

Biswas, S., Mondal, R., Mukherjee, A., Sarkar, M. and Kole, R.K., 2019. Simultaneous determination and risk assessment of fipronil and its metabolites in sugarcane, using GC-ECD and confirmation by GC-MS/MS. Food Chemistry, 272: 559-567. https://doi.org/10.1016/j.foodchem.2018.08.087.

Chen, X.X., Fan, X.Q., Ma, Y.C. and Hu, J.Y., 2018. Dissipation behaviour, residue distribution and dietary risk assessment of tetraconazole and kresoxim-methyl in greenhouse strawberry via RRLC-QqQ-MS/MS technique. Ecotoxicology and Safety, 148: 799-804. https://doi.org/10.1016/j.ecoenv.2017.11.019

Chen, X.J., Meng, Z.Y., Zhang, Y.Y., Gu, H.T., Ren, Y.J. and Lu, C.L., 2016. Degradation kinetics and pathways of spirotetramat in different parts of spinach plant and in the soil. Environmental Science and Pollution Research, 23: 15053-15062. https://doi. org/10.1007/s11356-016-6665-6

Chen, S.S., Zhou, M.X., Zhang, Z.F. and Zhang, W.B., 2017. New and convenient approach for synthesis of metconazole. Research on Chemical Intermediates, 43: 6293-6298. https://doi. org/10.1007/s11164-017-2989-1

Chinese Ministry of Agriculture, 2021. National food safety standardmaximum residue limits for pesticides in food, GB-2763-2021. Beijing China: Chinese Ministry of Agriculture (MOA).

Council of the European Union 2016. European pesticides database. Bruxelles, Brussel: EU. Available at: https://ec.europa.eu/ food/plant/pesticides/eu-pesticides-database/active-substances $/$ ?event=as.details\&as_id=211\#inline-nav-3.

Deng, Y., Liu, R., Wang, Z.K., Zhang, L.Y., Yu, S.M., Zhou, Z.Q. and Diao, J.L., 2021. The stereoselectivity of metconazole on wheat grain filling and harvested seeds germination: Implication for the application of triazole chiral pesticides. Journal of Hazardous Materials, 416: 1-11. https://doi.org/10.1016/j. jhazmat.2021.125911.

Duan, Y.B., Tao, X., Zhao, H.H., Xiao, X.M., Li, M. X., Wang, J.X. and Zhou, M.G., 2019. Activity of demethylation inhibitor fungicide metconazole on Chinese fusarium graminearum species complex and its application in carbendazim-resistance management of fusarium head blight in wheat. Plant Disease, 103: 929-937. https://doi.org/10.1094/PDIS-09-18-1592-RE.

Fantke, P. and Juraske, R., 2013. Variability of pesticide dissipation half-lives in plants. Environment Science and Technology, 47: 3548-35560. https://doi.org/10.1021/es303525x.

Food and Agriculture Organization/World Health Organization (FAO/WHO), 2009. Dietary exposure assessment of chemicals in food. In: Principles and methods for the risk assessment of chemicals in food. Rome, Italy: FAO, Chap 6, p. 98. ISBN 97892 4 157240 8, ISSN 0250-863X.

Freitas, L.A.D., Vieira, A.C., Mendonca, J.A.F.R. and Figueiredo, E.C., 2014. Molecularly imprinted fibers with renewable surface for solid-phase microextraction of triazoles from grape juice samples followed by gas chromatography mass spectrometry analysis. Analyst, 139: 626-632. https://doi. org/10.1039/C3AN01756G.

Grayson, B.T., Boyd, S.L., Sampson, A.J., Drummond, J. and Walter, D., 1995. Effect of adjuvants on the performance of the new cereal fungicide, metconazole. I glasshouse trials. Pesticide Science, 45: 153-160. https://doi.org/10.1002/ps.2780450209.

He, R., Fan, J., Tan, Q., Lai, Y., Chen, X., Wang, T., Jiang, Y., Zhang, Y. and Zhang, W. 2017. Enantio selective determination of metconazole in multi matrices by high-performance liquid chromatography. Talanta, 178: 980-986. http://dx.doi.org/10.1016/j. talanta.2017.09.045.

Hernandez, F., Cervera, M.I, Portoles, T., Beltran, J. and Pitarch, E., 2013. The role of GC-MS/MS with triple quadrupole in pesticide residue analysis in food and the environment. Analytical Methods, 5: 5875-5894. https://doi:10.1039/c3ay41104d.

Huang, J.X., Liu, C.Y., Lu, D.H., Chen, J.J., Deng, Y.C. and Wang, F.H., 2015. Residue behavior and risk assessment of mixed formulation of imidacloprid and chlorfenapyr in chieh-qua under field conditions. Environmental Monitoring and Assessment, 187, 650. http://dx.doi.org/10.1007/s10661-015-4846-2.

Jin, S.G., 2008. The tenth report of nutrition and health status for China residents: nutrition and health status of annual 2002. Beijing, China: People's Medical Publishing House.

Li, J., Duan, Y.B., Bian, C.H., Pan, X.Y., Yao, C.J., Wang, J.X. and Zhou, M.G., 2019. Effects of validamycin in controlling Fusarium head blight caused by Fusarium graminearum: inhibition of DON biosynthesis and induction of host resistance. Pesticide Biochemistry and Physiology, 153: 152-160. https:// doi.org/10.1016/j.pestbp.2018.11.012.

Li, Z.N., Li, F.F., Wei, Y., Fan, Y., Ma, Y., Wang, W., Liu, Y., Zhao, T., Lu, P., Zhang, Y.P. and Hu, D.Y., 2017a. Dissipation rates of saisentong residues in fresh tobacco, tobacco powder and soil determined by high-performance liquid chromatography coupled with diode array detection. International Journal of Environmental Analytical Chemistry, 97: 355-367. https://doi. org/10.1080/03067319.2017.1315111.

Li, R.J., Liu, T.J., Cui, S.H., Zhang, S.C., Yu, J.L. and Song, G.C., 2017b. Residue behaviors and dietary risk assessment of dinotefuran and its metabolites in Oryza sativa by a new HPLC-MS/ MS method. Food Chemistry, 235: 188-193. http://dx.doi. org/10.1016/j.foodchem.2017.04.181.

Liang, H.W., Li, L., Qiu, J., Li, W., Yang, S.M., Zhou, Z.Q. and Qiu, L.H., 2013. Stereo selective transformation of triadimefon to metabolite triadimenol in wheat and soil under field conditions. Journal of Hazardous Materials, 260: 929-936. https://doi. org/10.1016/j.jhazmat.2013.06.046.

Liu, S.M., Fu, L.Y., Chen, J.P., Wang, S., Liu, J.L., Jiang, J., Che, Z.P., Tian, Y. and Chen, G.Q., 2021. Baseline sensitivity of Sclerotiniasclerotiorum to metconazole and the analysis of cross-resistance with carbendazim, dimethachlone, boscalid, fluazinam, and fludioxonil. Phytoparasitica, 49: 123-130. https://doi.org/10.1007/s12600-020-00867-8.

Liu, G., Qiao, X., Tao, C., He, Y., Gong, Y., Qin, D., Zhu, G., Qin, S., Li, Y. and Song, W., 2004. Guideline on pesticide residue trials. The industry standard of P.R. China (NY/T 788-2004). China Agricultural Publisher, Beijing, China.

Lopez-Fernandez, O., Rial-Otero, R., Simal-Gandara, J. and Boned, J., 2016. Dissipation kinetics of pre-plant pesticides in greenhouse-devoted soils. Science of the Total Environment, 543: 1-8. https://doi.org/10.1016/j.scitotenv.2015.10.145. 
Ma, C., Liu, Z., Qi, Y., Wang, S.S., Cao, X.L., Wang, J., She, Y.X., Shao, Y.X., Shen, J.T. and Zhang, C., 2018. Residue behavior and risk assessment of thifluzamide in the maize field ecosystem. Environmental Science and Pollution Research, 25: 2119521204. https://doi.org/10.1007/s11356-018-2211-z.

Machado, S.C., Souza, B.M., Marciano, L.P.D., Pereira, A.F.S., De Carvaiho, D.T. and Martins, I., 2019. A sensitive and accurate vortex-assisted liquid-liquid microextraction-gas chromatography-mass spectrometry method for urinary triazoles. Journal of Chromatography A, 1586: 9-17. https://doi.org/10.1016/j. chroma.2018.11.082.

Malhat, F., Badawy, H., Barakat, D. and Saber, A., 2013. Determination of etoxazole residues in fruits and vegetables by SPE clean-up and HPLC-DAD. Journal of Environmental Science and Health, Part B 48: 331-335. https://doi.org/10.108 0/03601234.2013.742371.

Mondal, R., Kole, R.K. and Bhttacharyya, A., 2017. Validation of multiresidue method for analysis of 31 pesticides in rice using gas chromatography-tandem mass spectrometry. Journal of AOAC International, 100: 1094-1101. https://doi.org/10.5740/ jaoacinct.16-0377.

Shi, K.W., Li, W., Yuan, L.F., Li, L. and Liu, F.M., 2015. Dissipation, terminal residues and risk assessment of fluopicolide and its metabolite in cucumber under field conditions. Environmental Monitoring and Assessment, 187, 698. https://doi.org/10.1007/ s10661-015-4.924-5.

Shi, W.Q., Xiang, L.B., Yu, D.Z., Gong, S.J. and Yang, L.J., 2020. Impact of the biofungicide tetramycin on the development of Fusarium head blight, grain yield and deoxynivalenol accumulation in wheat. World Mycotoxin Journal, 13(2): 235- 246. https://doi.org/10.3920/WMJ2019.2494.

Singh, N. and Tandon, S., 2015. Dissipation kinetics and leaching of cyazofamid fungicide in texturally different agricultural soils. International Journal of Environmental Science and Technology, 12: 2475-2484. https://doi.org/10.1007/s13762-014-0608-x.

Szpyrka, E., Kurdziel, A., Matyaszek, A., Podbielska, M., Rupar, J. and Słowik-Borowiec, M., 2015. Evaluation of pesticide residues in fruits and vegetables from the region of south-eastern Poland. Food Control, 48: 137-142. http://dx.doi.org/10.1016/j. foodcont.2014.05.039.

Tateishi, H., Miyake, T., Mori, M., Sakuma, Y. and Saishoji, T., 2014. Effect of application timing of metconazole on Fusarium head blight development and mycotoxin contamination in wheat and barley. Journal of Pesticide Science, 39: 1-6. http:// doi: 10.1584/ jpestics. D12-077.

Telenko, D.E.P., Ravellette, J.D. and Wise, K.A., 2020. Assessing late vegetative and tasseling fungicide application timings on foliar disease and yield in Indiana corn. Plant Health Progress, 21: 4. https://doi.org/10.1094/PHP-03-20-0022-RS.

United States Environmental Protection Agency (USEPA), 2007. Pesticide fact sheet. Office of Prevention, Pesticides and Toxic Substances, Washington, DC. Available at: https://nepis.epa. gov/Exe/ZyPURL.cgi?Dockey=P100C251.txt.

Wang S.W., Sun H.B. and Liu Y.P., 2018a. Residual behavior and risk assessment of tridemorph in banana conditions. Food Chemistry, 244: 71-74. http://dx.doi.org/10.1016/j. foodchem.2017.09.124

Wang, S.Y., Zhang, Q.T., Yu, Y.R., Chen, Y., Zeng, S., Lu, P. and Hu, D.Y., 2018b. Residues, dissipation kinetics, and dietary intake risk assessment of two fungicides in grape and soil. Regulatory Toxicology and Pharmacology, 100: 72-79. https:// doi.org/10.1016/j.yrtph.2018.10.015.

World Health Organization (WHO), 2015. A template for the automatic calculation of the IESTI. Available at: http://www.who.int/ foodsafety/areas_work/chemical-risks/gems-food/en

Zhang, Y.P., Hu, D.Y., Zeng, S., Lu, P., Zhang, K.K., Chen, L.Z. and Song, B.A., 2016a. Multiresidue determination of pyrethroid pesticide residues in pepper through a modified QuEChERS method and gas chromatography with electron capture detection. Biomedical Chromatography, 30: 142-148. http://dx.doi. org/ 10.1002/bmc.3528.

Zhang, K.K., Tang, M.M., Zhang, J., Li, Y.J., Han, X.W., Pan, S.Z., Kong, X.X., Li, M.C., Chen, H.Y., Zhang, W., H.J., Zhu, S. Zeng and $\mathrm{Hu}, \mathrm{D} . Y ., 2016 \mathrm{~b}$. Fate of hexaconazole and isoprothiolane in rice, soil and water under field conditions. International Journal of Environmental Analytical Chemistry, 96: 38-49. https://doi. org/10.1080/03067319.2015.1128535.

Zhu, J.M., Zhang, L.Y., Li, T.T., Ma, D.C., Gao, Y.Y., Mu, W. and Liu, F., 2020. Baseline sensitivity of corynesporacassiicola to metconazole and efficacy of this fungicide. Crop Protection, 130: 1-7. https://doi.org/10.1016/j.cropro.2019.105056. 


\section{Supplementary Material}

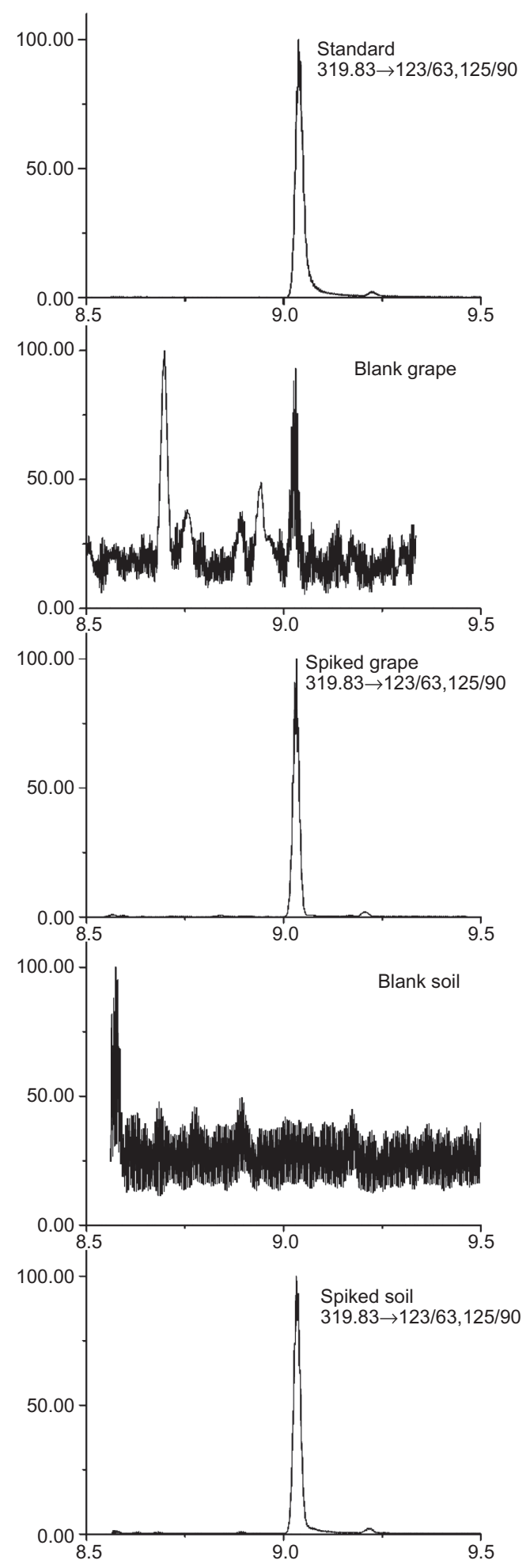

Figure S1. GC-MS/MS chromatograms of metconazole in standard solution $(0.2 \mathrm{mg} / \mathrm{L})$, blank grape, blank soil, spiked grape and soil samples $(0.02 \mathrm{mg} / \mathrm{kg})$. 
Table S1. Data for orthogonal experimental design (grapes).

\begin{tabular}{|c|c|c|c|c|c|c|}
\hline Array factor & $\begin{array}{c}\text { A } \\
\text { (Solvent) }\end{array}$ & $\begin{array}{c}\text { B } \\
\text { (Volume, mL) }\end{array}$ & $\begin{array}{c}\mathrm{C} \\
\text { (Extract time, } \mathrm{min})\end{array}$ & $\begin{array}{c}\text { D } \\
\text { (Sorbent) }\end{array}$ & $\begin{array}{c}\text { Recovery }{ }^{\mathrm{a}, \mathrm{b}} \\
(\%)\end{array}$ & $\begin{array}{l}\text { RSD } \\
(\%)\end{array}$ \\
\hline 1 & 1 (ethyl acetate) & $1(10 \mathrm{~mL})$ & $1(1)$ & 1 (PSA + C18) & 75.63 & 3.01 \\
\hline 2 & 1 (ethyl acetate) & $2(20 \mathrm{~mL})$ & $2(3)$ & 2 (PSA) & 72.54 & 2.33 \\
\hline 3 & 1 (ethyl acetate) & $3(30 \mathrm{~mL})$ & $3(5)$ & $3(\mathrm{C} 18)$ & 66.31 & 8.37 \\
\hline 4 & 2 (acetonitrile) & $1(10 \mathrm{~mL})$ & $2(3)$ & $3(\mathrm{C} 18)$ & 82.16 & 3.66 \\
\hline 5 & 2 (acetonitrile) & $2(20 \mathrm{~mL})$ & $3(5)$ & 1 (PSA + C18) & 95.32 & 3.13 \\
\hline 6 & 2 (acetonitrile) & $3(30 \mathrm{~mL})$ & $1(1)$ & 2 (PSA) & 85.67 & 4.88 \\
\hline 7 & 3 (dichloromethane) & $1(10 \mathrm{~mL})$ & $3(5)$ & 2 (PSA) & 64.58 & 3.49 \\
\hline 8 & 3 (dichloromethane) & $2(20 \mathrm{~mL})$ & $1(1)$ & 3 (C18) & 60.53 & 7.37 \\
\hline 9 & 3 (dichloromethane) & $3(30 \mathrm{~mL})$ & $2(3)$ & $1(\mathrm{PSA}+\mathrm{C} 18)$ & 52.98 & 5.42 \\
\hline Average 1 & $71.49 \%$ & $74.12 \%$ & $73.94 \%$ & $74.64 \%$ & - & - \\
\hline Average 2 & $87.72 \%$ & $76.13 \%$ & $69.23 \%$ & $74.26 \%$ & - & - \\
\hline Average 3 & $59.36 \%$ & $68.32 \%$ & $75.40 \%$ & $69.67 \%$ & - & - \\
\hline Range & $28.35 \%$ & $7.81 \%$ & $6.18 \%$ & $4.98 \%$ & - & - \\
\hline
\end{tabular}

${ }^{a}$ Average recovery of three experiments.

${ }^{b} 1 \mathrm{~mL}$ of $0.20-\mu \mathrm{g} / \mathrm{mL}$ standard sample.

RSD: relative standard deviation; PSA: primary secondary amine.

Table S2. Orthogonal experimental analysis of variance ( $\alpha=0.1$ ) (grapes).

\begin{tabular}{lccccc} 
Factor & Sum of square of deviations & Degree of freedom & $F$ ratio & $F$ critical value & Significance \\
\hline A & 1214.24 & 2 & 3.417 & 3.110 & - \\
B & 98.70 & 2 & 0.278 & 3.110 & - \\
C & 62.53 & 2 & 0.176 & 3.110 & - \\
D & 46.04 & 2 & 0.130 & 3.100 & - \\
Error & 1421.51 & 8 & 1 & $/$ & - \\
\hline
\end{tabular}

Table S3. Data for orthogonal experimental design (soil).

\begin{tabular}{|c|c|c|c|c|c|c|}
\hline Array factor & $\begin{array}{c}\text { A } \\
\text { (Solvent) }\end{array}$ & $\begin{array}{c}\text { B } \\
\text { (Volume, } \mathrm{mL} \text { ) }\end{array}$ & $\begin{array}{c}\mathrm{C} \\
\text { (Extract time, } \mathrm{min})\end{array}$ & $\begin{array}{c}\text { D } \\
\text { (Sorbent) }\end{array}$ & Recovery $^{\mathrm{a}, \mathrm{b}}(\%)$ & RSD (\%) \\
\hline 1 & 1 (ethyl acetate) & $1(10 \mathrm{~mL})$ & $1(1)$ & 1 (PSA + C18) & 77.40 & 5.29 \\
\hline 2 & 1 (ethyl acetate) & $2(20 \mathrm{~mL})$ & $2(3)$ & 2 (PSA) & 79.77 & 4.78 \\
\hline 3 & 1 (ethyl acetate) & $3(30 \mathrm{~mL})$ & $3(5)$ & $3(\mathrm{C} 18)$ & 72.19 & 4.23 \\
\hline 4 & 2 (acetonitrile) & $1(10 \mathrm{~mL})$ & $2(3)$ & 3 (C18) & 82.24 & 4.71 \\
\hline 5 & 2 (acetonitrile) & $2(20 \mathrm{~mL})$ & $3(5)$ & 1 (PSA + C18) & 96.34 & 1.03 \\
\hline 6 & 2 (acetonitrile) & $3(30 \mathrm{~mL})$ & $1(1)$ & 2 (PSA) & 75.56 & 6.35 \\
\hline 7 & 3 (dichloromethane) & $1(10 \mathrm{~mL})$ & $3(5)$ & 2 (PSA) & 61.36 & 5.83 \\
\hline 8 & 3 (dichloromethane) & $2(20 \mathrm{~mL})$ & $1(1)$ & 3 (C18) & 57.58 & 3.92 \\
\hline 9 & 3 (dichloromethane) & $3(30 \mathrm{~mL})$ & $2(3)$ & $1(\mathrm{PSA}+\mathrm{C} 18)$ & 51.46 & 6.69 \\
\hline Average 1 & $76.45 \%$ & $73.67 \%$ & $70.18 \%$ & $75.07 \%$ & - & - \\
\hline Average 2 & $84.71 \%$ & $77.90 \%$ & $71.16 \%$ & $72.23 \%$ & - & - \\
\hline Average 3 & $56.80 \%$ & $66.40 \%$ & $76.63 \%$ & $70.67 \%$ & l & 1 \\
\hline Range & $27.91 \%$ & $11.49 \%$ & $6.45 \%$ & $4.40 \%$ & - & - \\
\hline
\end{tabular}

${ }^{a}$ Average recovery of three experiments.

${ }^{b} 1 \mathrm{~mL}$ of $0.20-\mu \mathrm{g} / \mathrm{mL}$ standard sample.

RSD: relative standard deviation; PSA: primary secondary amine. 
Table S4. Orthogonal experimental analysis of variance $(\alpha=0.1)$ (soil).

\begin{tabular}{lrcccc} 
Factor & Sum of square of deviations & Degree of freedom & F-ratio & F-critical value & Significance \\
\hline A & 1233.64 & 2 & 3.207 & 3.110 & - \\
B & 202.75 & 2 & 0.527 & 3.110 & - \\
C & 72.51 & 2 & 0.188 & 3.110 & - \\
D & 29.81 & 2 & 0.077 & 3.100 & - \\
Error & 1538.71 & 8 & - & - \\
\hline
\end{tabular}

Table S5. Terminal residues of metconazole in grapes and soil.

\begin{tabular}{|c|c|c|c|c|c|c|c|}
\hline \multirow[t]{3}{*}{ Location } & \multirow{3}{*}{$\begin{array}{l}\text { Dosage } \\
\text { (g a.i/ha) }\end{array}$} & \multirow{3}{*}{$\begin{array}{l}\text { Spray } \\
\text { times }\end{array}$} & \multirow[t]{3}{*}{ Interval (days) } & \multicolumn{4}{|c|}{ Mean \pm SD (mg/kg) } \\
\hline & & & & \multicolumn{2}{|c|}{2016} & \multicolumn{2}{|c|}{2017} \\
\hline & & & & Grapes & Soil & Grapes & Soil \\
\hline \multirow[t]{12}{*}{ Guizhou } & 60 & 2 & 7 & $0.18 \pm 0.03$ & $0.03 \pm 0.02$ & $0.14 \pm 0.03$ & $0.03 \pm 0.02$ \\
\hline & & & 14 & $<0.002$ & $0.01 \pm 0.01$ & $<0.002$ & $0.02 \pm 0.01$ \\
\hline & & & 21 & $<0.002$ & $0.01 \pm 0.01$ & $<0.002$ & $0.01 \pm 0.00$ \\
\hline & & 3 & 7 & $0.09 \pm 0.05$ & $0.02 \pm 0.00$ & $0.19 \pm 0.12$ & $0.01 \pm 0.00$ \\
\hline & & & 14 & $<0.002$ & $<0.002$ & $0.02 \pm 0.02$ & $<0.002$ \\
\hline & & & 21 & $<0.002$ & $<0.002$ & $<0.002$ & $<0.002$ \\
\hline & 90 & 2 & 7 & $0.13 \pm 0.02$ & $<0.002$ & $0.14 \pm 0.01$ & $<0.002$ \\
\hline & & & 14 & $<0.002$ & $<0.002$ & $<0.002$ & $<0.002$ \\
\hline & & & 21 & $<0.002$ & $<0.002$ & $<0.002$ & $<0.002$ \\
\hline & & 3 & 7 & $0.01 \pm 0.00$ & $<0.002$ & $0.10 \pm 0.00$ & $<0.002$ \\
\hline & & & 14 & $<0.002$ & $<0.002$ & $<0.002$ & $<0.002$ \\
\hline & & & 21 & $<0.002$ & $0.01 \pm 0.00$ & $<0.002$ & $<0.002$ \\
\hline \multirow[t]{12}{*}{ Anhui } & 60 & 2 & 7 & $0.04 \pm 0.01$ & $0.02 \pm 0.00$ & $0.04 \pm 0.01$ & $0.03 \pm 0.00$ \\
\hline & & & 14 & $0.03 \pm 0.03$ & $0.01 \pm 0.00$ & $0.01 \pm 0.00$ & $0.02 \pm 0.01$ \\
\hline & & & 21 & $0.02 \pm 0.02$ & $0.01 \pm 0.01$ & $0.02 \pm 0.00$ & $0.02 \pm 0.01$ \\
\hline & & 3 & 7 & $0.03 \pm 0.00$ & $0.02 \pm 0.00$ & $0.03 \pm 0.00$ & $0.03 \pm 0.00$ \\
\hline & & & 14 & $0.03 \pm 0.01$ & $0.01 \pm 0.00$ & $0.03 \pm 0.01$ & $0.02 \pm 0.01$ \\
\hline & & & 21 & $0.02 \pm 0.00$ & $0.01 \pm 0.00$ & $0.02 \pm 0.00$ & $0.02 \pm 0.01$ \\
\hline & 90 & 2 & 7 & $0.03 \pm 0.00$ & $0.03 \pm 0.03$ & $0.04 \pm 0.01$ & $0.04 \pm 0.01$ \\
\hline & & & 14 & $0.01 \pm 0.00$ & $0.02 \pm 0.02$ & $0.07 \pm 0.00$ & $0.02 \pm 0.00$ \\
\hline & & & 21 & $0.02 \pm 0.00$ & $0.01 \pm 0.01$ & $0.02 \pm 0.02$ & $0.01 \pm 0.00$ \\
\hline & & 3 & 7 & $0.02 \pm 0.01$ & $0.03 \pm 0.03$ & $0.06 \pm 0.01$ & $0.04 \pm 0.00$ \\
\hline & & & 14 & $0.02 \pm 0.00$ & $0.05 \pm 0.05$ & $0.04 \pm 0.04$ & $0.06 \pm 0.01$ \\
\hline & & & 21 & $0.03 \pm 0.01$ & $0.02 \pm 0.02$ & $0.02 \pm 0.01$ & $0.02 \pm 0.01$ \\
\hline
\end{tabular}

